\title{
Refigurações narrativas discentes nas aulas de História: reflexões sobre aprendizagens dessa disciplina escolar
}

Narrative Refigurations of Students in History Lessons: Thoughts on the Learning of the Subject

Marcus Leonardo Bomfim Martins ${ }^{\star}$ Alexandre Rodrigues de Frias Barbosa ${ }^{* *}$ Carmen Teresa Gabriel ${ }^{\star * *}$

\section{RESUMO}

O objetivo deste artigo é problematizar processos de aprendizagens da História escolar. Situado em uma abordagem pós-fundacional, ele se inscreve nas lutas pela significação e fixação de um sentido particular do ato de aprender História. Em diálogo com autores que nos oferecem pistas para pensar de outro lugar epistêmico o processo de aprendizagem, em geral, e da disciplina História, em particular, o artigo explora a interface de três categorias - relação com o saber, verdade histórica e refiguração narrativa - como chaves de leitura para um entendimento possível desse processo. A empiria é constituída por um conjunto de fragmentos narrativos produzidos por estudantes da educação básica em aulas de História. A análise reafirma a possibilidade de compreensão da aprendizagem histórica para

\section{ABSTRACT}

The purpose of this article is to discuss the learning processes of History in schools. Based on a post-foundational approach, it is part of the battles for the significance and the fixation of a particular sense of History learning. In connection with authors who offer us clues to reflect on the learning process in general and the learning of History in particular from other epistemic places, the article explores the interface between three categories - relationship with knowledge, historical truth and narrative refiguration - as the keys for a possible understanding of this process. The empirical basis is built from a collection of narrative fragments, given by elementary school students in History lessons. The analysis reaffirms the possibilities of understanding History learning as more than the acquisition of

\footnotetext{
* Universidade Federal de Juiz de Fora (UFJF), Juiz de Fora, MG, Brasil. marcus.bomfim@gmail.com **Universidade Federal do Rio de Janeiro(UFRJ), Rio de Janeiro, RJ, Brasil. alexandrerodriguesfb@ hotmail.com

*** Universidade Federal do Rio de Janeiro(UFRJ), Rio de Janeiro, RJ, Brasil.carmenteresagabriel@ gmail.com
} 
além de aquisições de conhecimentos disciplinares, evidenciando processos multidimensionais que se inscrevem na cultura histórica e na cultura escolar. Palavras-chave: aprendizagem histórica; cultura histórica; cultura escolar. knowledge by showcasing multidimensional processes within historical and school culture.

Keywords: History learning; historical culture; school culture.

[...] podemos dizer que alguém aprendeu alguma coisa não quando for capaz de copiar e produzir o que já existia, mas quando alguém responde ao que não é familiar, ao que é diferente, ao que desafia, irrita ou até perturba. Então a aprendizagem se torna uma criação ou uma invenção, um processo de introduzir algo novo no mundo: a resposta única de alguém. (BIESTA, 2017, p. 97)

Tanto o título atribuído a este texto quanto a citação de Biesta (2017), escolhida como epígrafe, traduzem de forma clara e direta a linha de argumentação que procuraremos sustentar ao longo deste artigo sobre o ato de aprender no âmbito da disciplina escolar História. Isso não significa, no entanto, que esse entendimento seja o único possível, tampouco o mais verdadeiro. O que seriam aprendizagens em História? Ou, ainda, como questionava-se Moniot (1993), em função da especificidade de sua natureza epistemológica, a História seria uma disciplina ensinável? Seu conteúdo seria de fácil apreensão e transmissão entre gerações?

No quadro teórico pós-fundacional (MARCHART, 2009) com o qual operamos, não existe uma possibilidade unívoca de resposta a esses questionamentos. Na postura epistêmica aqui privilegiada, pesquisar ou refletir sobre aprendizagem em História diz respeito a participar do jogo político atual pela própria definição de cada um desses termos. Afinal, a que grupo de interesses uma determinada definição particular de aprendizagem em História "serve"? Que debates estratégicos do campo do Ensino de História (como os que envolvem os objetivos desta disciplina, as singularidades epistemológicas do conhecimento histórico escolar, os processos de seleção curricular, as formas de tornar o conhecimento histórico inteligível) a defesa de uma determinada definição de aprendizagem reatualiza? 
Embora questões relacionadas à aprendizagem tenham sido colocadas por pesquisadores inscritos em diferentes movimentos teóricos da área de ensino dessa disciplina há mais de quatro décadas (MONIOT, 1993; AILLEU, 1995; MONTEIRO 2002; GABRIEL, 2003; MARTINS, 2019; SCHMIDIT, 2009; CAINELLI, 2006; WANDERLEY, 2016), essa temática assume em nosso presente contornos particulares em função dos efeitos no campo educacional da conjuntura política atual, marcada pela hegemonização do modelo neoliberal. Esses efeitos extrapolam o campo do Ensino da História, trazendo para o debate as disputas em torno do próprio sentido do processo de ensino-aprendizagem, à despeito da matriz disciplinar a que ele esteja articulado.

Nas políticas educacionais atuais, questões sobre o conteúdo e o objetivo da educação - que interferem diretamente na problemática da aprendizagem - são formuladas em termos do que o "cliente" (estudante) ou o "mercado" desejam, secundarizando ou mesmo impossibilitando uma discussão aberta e democrática sobre o conteúdo e o objetivo da educação. Com efeito, a erosão do Estado de bem-estar social pela intensificação da ideologia de mercado neoliberal fortalece o deslocamento da ênfase de uma relação política para uma relação econômica, na qual a mercadoria é a educação.

Nessa perspectiva, uma linguagem da aprendizagem - percebida como sinônimo de consumo de conhecimentos-objetos com vistas a garantir a reprodução de uma comunidade racional que invisibiliza sujeitos e impedem que eles se "tornem presença" (BIESTA, 2017) ou produzam "saberes de experiência” (BONDÍA, 2002) - se fortalece e passa a ocupar um lugar de destaque no debate político. Não é por acaso que Freitas (2016), ao denunciar essa perspectiva da aprendizagem, a significa como

[...] movimento de absorver e deglutir informações e conhecimentos, mas sem incorporá-los (torná-los corpo), de modo que, não por acaso, ocorre o esquecimento, a recusa ou a desatenção em relação aos conteúdos. No máximo o sujeito os devolve, à semelhança da bulimia, no cumprimento de uma função (passar de ano ou em uma prova). (FREITAS, 2016, p. 582, grifos nossos)

Como mencionado anteriormente, o fio argumentativo sustentado ao longo deste texto vai de encontro a esse entendimento de aprendizagem. Optamos, assim, por apostar no investimento em sentidos desse significante que desestabilizam e ampliam sua cadeia de equivalências hegemonizada na conjuntura 
educacional contemporânea atravessada pelas lógicas da aquisição e da mensuração. Em diálogo com autores que nos oferecem pistas de investigação para pensar de outro modo o processo de aprendizagem, em geral, e no âmbito da disciplina História, em particular, apostamos na potência analítica da interface de três categorias - relação com o saber, verdade histórica e refiguração narrativa. Para tal, exploramos empiricamente um conjunto de fragmentos narrativos produzidos por alunos/as da educação básica no âmbito de aulas de História, buscando sublinhar o processo de aprendizagem que os fragmentos encerram.

Organizamos nossos argumentos em três blocos de reflexão. O primeiro apresenta de forma sintética nossa interpretação do debate sobre a temática da aprendizagem no campo do Ensino de História, explicitando nossa posição político-epistemológica no enfrentamento dos desafios que o debate suscita. No segundo bloco, apresentamos nossa compreensão sobre as categorias analíticas anteriormente mencionadas, bem como os seus desdobramentos no debate teórico dos campos da História e do Ensino de História, em particular no que elas incidem sobre a questão da aprendizagem dessa e nessa disciplina escolar. No terceiro bloco, interpretamos processos de aprendizagem a partir de refigurações narrativas discentes produzidas em aulas de História do Ensino Fundamental, tendo como ferramenta de análise as categorias anteriormente mencionadas.

\section{APRENDIZAGENS EM HISTÓRIA: SENTIDOS EM DISPUTA}

Trata-se de uma perspectiva que, em lugar de conceber o ensino de História e a aprendizagem histórica como pertencentes a um lugar de fronteira, os concebem como um território em guerra civil, em que diferentes forças políticas disputam pela jurisdição de uma área comum. Essa perspectiva marca a diferença entre os trabalhos que se associam à Educação Histórica e à Didática da História, que apresentam uma concepção disciplinar e os que, divergindo dessa posição, se orientam por um olhar mais amplo acerca dos processos de aprendizagem histórica, que acabam por apresentar-se opostamente, em uma concepção interdisciplinar. (MISTURA, 2019, p. 108)

Nosso propósito nesste primeiro bloco, longe de pretender apresentar um estado da arte sobre essa temática no campo do Ensino da História, consiste em explicitar uma perspectiva para ver e entrar no debate que a mesma invo- 
ca e provoca. Uma perspectiva que, como afirma Mistura (2019) na citação acima, reconhece o conflito e as disputas entre diferentes grupos que configuram a comunidade disciplinar (COSTA e LOPES, 2016) que participa do jogo político em torno da definição dos significantes aprendizagem e História. Ainda que nosso interesse seja menos de mapear tais disputas do que significá-las como elemento incontornável na leitura política do fenômeno estudado, reconhecemos que o desenho dessas lutas entre dois campos ou perspectivas descritas por essa autora encontra eco junto aos pesquisadores da área.

Em pesquisa realizada no Banco de Teses da Capes, com recorte nas áreas de História, Educação e Ensino de História, a partir do significante aprendizagem histórica (e outros inscritos no mesmo campo semântico), Martins (2019) constatou a presença de pesquisas que valorizam as dimensões didáticas/pedagógicas e pesquisas que as desqualificam no processo de validação de aprendizagens no âmbito da disciplina escolar História. Enquanto as primeiras tendem a destacar o caráter específico do conhecimento escolar e seu processo de configuração a partir da ciência de referência, e em relação a saberes pedagógicos e das ciências da Educação, as outras defendem que este conhecimento, mesmo no "chão da escola", deve estar subsumido apenas aos modos de produção de saberes no âmbito da História, colocando a didática como exterior constitutivo do processo de aquisição/produção de aprendizagens históricas significativas.

Esses estudos, relativamente recentes, apontam igualmente para essas duas perspectivas que tendem a apresentar-se como abordagens rivais, traduzindo tendências de grupos de pesquisa determinados, com marcas territoriais bastante acentuadas. Martins (2019) sublinha o lugar de destaque ocupado pelos pesquisadores de instituições como a UFPR e a FURG na produção de teses e dissertações que mobilizam o termo aprendizagem histórica. Segundo esse autor, as pesquisas sobre essa temática desenvolvidas nos laboratórios de pesquisa dessas universidades possuem como marca comum a mobilização de referencial teórico-metodológico inspirado tanto em estudos da Didática da História de matrizes alemã e/ou inglesa nos quais as produções do historiador Jörn Rüsen assumem centralidade, constituindo uma área de estudos chamada, no Brasil, de Educação Histórica. ${ }^{1}$ De forma semelhante, em trabalho voltado exclusivamente para a produção de um estado do conhecimento sobre aprendizagem histórica em teses e dissertações no Brasil, Mistura (2019) iden- 
tifica o mesmo quadro geral apontado por Martins (2019), acrescentando também a UEL como local de destaque dessa produção.

Essas investigações que se orientam, como sugere Mistura (2019), por uma perspectiva disciplinar, manifestam suas posições de três modos: i) por meio de afirmação irrestrita da História como disciplina de pertencimento das discussões sobre aprendizagem histórica; ii) por meio de construções críticas ou denunciativas de outras abordagens; iii) por uma combinação de ambas as modalidades argumentativas. Importa observar que, mesmo nas pesquisas inscritas no campo da Educação Histórica que dialogam com autores de outras áreas como a da Psicologia da Educação, deixando entrever uma possibilidade de interlocução com outros campos disciplinares, e por esta razão nomeadas por Mistura (2019) como pesquisas “desviantes”, o que predomina é a defesa da exclusividade epistemológica da História como conhecimento que une e reforça os laços entre a Teoria da História de Rüsen e os estudos da Educação Histórica na definição/explicação das aprendizagens históricas.

No que se refere às pesquisas no campo do Ensino de História com foco na aprendizagem - que, segundo Mistura (2019), inscrevem-se em um movimento interdisciplinar (CAIMI, 2006; MONTEIRO, 2007; GABRIEL, 2003; ROCHA, 2006; MARTINS, 2019), valorizando assim a posição fronteiriça da Didática da História entre a cultura escolar e a cultura histórica -, a fronteira entre o que está sendo e o que não está sendo chamado de aprendizagem em História é outra. Trata-se de reconhecer a potência da articulação entre as diferentes contribuições teóricas das áreas de conhecimento e simultaneamente apostar na possibilidade de repensar essa articulação de forma horizontal e não binária, desestabilizando, assim, sistemas de saberes socialmente hierarquizados. O que está em jogo nas querelas entre essas diferentes abordagens sobre a Didática da História é a disputa pelo lugar da demarcação de fronteiras definidoras de História, dos processos de ensino e aprendizagem, de aprendizagem em História. Disputa essa que nos fala dos interesses defendidos e das lutas escolhidas nos próprios campos da História e do Ensino de História.

Enquanto os defensores da Educação Histórica lutam pela afirmação e legitimação, no campo da História, de pesquisas que tangenciam a questão da socialização e distribuição dos conhecimentos históricos produzidos na academia, para os estudos que apostam na hibridização das contribuições teóricas de diferentes matrizes disciplinares, o que está em jogo é a contribuição parti- 
cular dessa área disciplinar aos processos de subjetivação que ocorrem em contextos de formação específicos. Nessa segunda perspectiva interessaria menos uma disputa entre historiadores e professores de História - o que reafirmaria campos de interesse distintos e antagônicos, tais como pesquisa e ensino, teoria e prática, teoria e didática da História - do que a luta pela construção e consolidação de um campo de pesquisa em Ensino de História cujos objetos e problemas de investigação, bem como as categorias de análise, escapassem dos binarismos que atravessam esses debates.

Ao distanciar-se de perspectivas deterministas e essencialistas que tendem a operar com percepções dicotômicas e excludentes, as pesquisas desenvolvidas na pauta pós-fundacional têm oferecido ferramentas de análise para a produção de leituras políticas do social, ampliando nosso campo de possibilidades para a reflexão sobre aprendizagens em História. Desse modo, mais do que um posicionamento favorável ou contrário a uma ou outra das abordagens anteriormente apresentadas, entendemos como mais produtiva uma busca por estratégias discursivas no próprio campo de pesquisa no qual nos inscrevemos que permitam fazer trabalhar certas aporias clássicas e entrar na disputa pela hegemonização de sentidos particulares de significantes que, embora estejam sob rasura (HALL, 2000), consideramos como incontornáveis para a análise pretendida. Essa forma de enfrentamento parece-nos importante, pois concordamos com Caimi (2015), que afirma que é preciso

[...] superar a crença de que o conhecimento científico específico contém, em si mesmo, as chaves de sua própria compreensão e difusão. De outro lado, há que desconfiar da ideia de que a didática dá conta da tarefa de ensinar tudo a todos, como postulava Comenius ainda no século XVI, independentemente dos saberes da ciência de referência. (CAIMI, 2015, p. 21)

QUE ENTENDIMENTO DE HISTÓRIA PARA

QUAL SENTIDO DE APRENDIZAGEM?

[...] a prática da narrativa consiste numa experiência de pensamento através da qual nos exercitamos a habitar mundos estranhos a nós mesmos. Nesse sen- 
tido, a narrativa exercita mais a imaginação do que a vontade, embora continue sendo uma categoria da ação. (RICOEUR, 1997, p. 428)

A questão formulada como título para o segundo bloco de reflexões explicita a importância da dimensão relacional na postura epistêmica pós-fundacional aqui assumida. Como já explicitado, não operamos com a ideia de sentidos fixados aprioristicamente como verdades metafísicas e absolutas. Cada um desses termos faz parte de uma rede discursiva tecida contingencialmente em meio às lutas entre os diferentes grupos de interesse que participam do jogo político de sua definição. Nessas redes discursivas, nas quais são produzidos e fixados sentidos de História e de aprendizagem, são mobilizados entendimentos particulares de objeto de conhecimento e de sujeito de aprendizagem que não podem ser negligenciados na reflexão em tela.

A explicitação dos sentidos particulares desses termos, tais como mobilizados em nossas pesquisas, parece-nos igualmente indispensável. Desse modo, temos apostado na articulação das categorias relação com o saber, verdade histórica e refiguração narrativa como estratégia potente para tal explicitação, bem como para o enfrentamento da interrogação-subtítulo. Trata-se de analisar como os sujeitos posicionados como discentes apropriam-se e refiguram as narrativas históricas legitimadas pelos regimes de verdade em voga nessa área disciplinar que os interpelam na sala de aula. Dito de outra forma, interessa-nos compreender a relação com o saber histórico estabelecida pelos discentes da educação básica. Afinal, a que processos de objetivação do conhecimento histórico legitimado como objeto de ensino-aprendizagem e a que processos de subjetivação acionados em uma aula de História articula-se a questão da aprendizagem?

No que diz respeito à potência analítica da categoria relação com o saber, destacamos a possibilidade que a mesma oferece para abordar a questão da aprendizagem para além do processo de aquisição de um conteúdo disciplinar específico sem, contudo, negar a sua importância. A despeito da matriz epistêmica na qual essa expressão é pensada, ao colocar o foco da reflexão na relação entre sujeitos e saberes, ela amplia o campo de possibilidades de qualificar ou definir a própria natureza dessa relação envolvendo outras dimensões que extrapolam os limites do aspecto cognitivo. 
A incorporação das contribuições do pós-fundacionismo, em nossos estudos, abre a possibilidade de outras interpretações dessa categoria de forma a romper radicalmente com a dicotomia sujeito e saber. Nessa perspectiva, buscamos ressignificar, para além dos termos saber e sujeito, o próprio significante relação. Interessa-nos focalizar as práticas articulatórias que definem a relação contingencial e provisória entre sujeito e saber em determinados contextos discursivos. Sentidos de sujeito e saber não são previamente estabelecidos antes de colocarem-se em relação. Operamos, assim, com o entendimento amplo dessa relação como sendo aquela que permite-nos acessar ao mundo por meio de processos ou sistemas de significação produzidos em um espaço-tempo específico. Essa compreensão, além de ampliar a cadeia de definição do termo saber, evidencia a importância do contexto para pensar a dimensão social dessa categoria. Em sintonia com a postura epistêmica assumida, não se trata de estabelecer uma ligação entre duas essências (sujeito e saber), de forma que "é a própria relação que precisa ser considerada logo de saída" (CHARLOT apud GABRIEL, 2018, p. 239).

Reconhecer que a apropriação do saber-objeto é apenas uma entre outras tantas figuras do aprender oferece a possibilidade de explorar a relação com o conhecimento como "uma relação epistêmica e identitária que opera com múltiplos sentidos ou figuras de aprendizagem" (GABRIEL, 2018, p. 241-242). Dito de outra forma, o potencial heurístico dessa categoria está em pensar a relação como lugar de emergência do sujeito e do saber, pois "um saber tem sentido e valor somente em referência às relações que o sujeito produz com o mundo, consigo e com os outros" (GABRIEL, 2018, p. 242). Esse entendimento, por sua vez, oferece possibilidades de problematização e ampliação do que Biesta (2017) denuncia como linguagem da aprendizagem.

Focalizar a questão da aprendizagem em História implica pensar na natureza da relação estabelecida com o saber histórico pelos sujeitos posicionados como alunos/as em uma aula dessa disciplina escolar a partir de entendimentos particulares, nos quais interessa-nos investir em cada um desses termos envolvidos: saber histórico, discente e o próprio significado da articulação entre eles. Que possibilidades de relações com o mundo, com o outros e consigo mesmo podem ser mobilizadas nas aulas de História? Que aprendizagens essas relações promovem?

$\mathrm{Na}$ abordagem aqui privilegiada, é justamente em meio à essa relação que 
ocorrem os processos de objetivação da História ensinada e de subjetivação do sujeito-discente. Embora não seja o foco deste texto, importa sublinhar que estamos falando de uma relação que se constrói em contexto escolar e que, portanto, pressupõe necessariamente a mediação de outros sujeitos que estabelecem outras relações como o saber histórico. A relação com o saber produzida do lugar do aluno/a é, pois, entremeada por relações com o conhecimento histórico produzido por outros sujeitos, em particular os posicionados como docentes no contexto da sala de aula. $\mathrm{O}$ ato de aprender, no contexto escolar, pressupõe a ação de ensinar.

Mas com qual entendimento de saber histórico escolar, resultante da articulação entre processos de objetivação e subjetivação em contextos de sala de aula, operamos para sustentar a compreensão de aprendizagem aqui defendida? Não cabe nos limites deste texto um aprofundamento do debate da área sobre a natureza e produção do conhecimento histórico legitimado como objeto de ensino-aprendizagem na educação básica. Reconhecendo que são muitas as portas de entrada possíveis para a discussão, optamos por assumir a estrutura narrativa do pensamento histórico (RICOEUR, 1997) na perspectiva do pós-fundacionismo (BEVIR, 2015) como chave de leitura para a análise aqui pretendida.

Essa opção autoriza a compreensão da produção do conhecimento histórico escolar como sendo uma reelaboração político-epistemológica de narrativas históricas produzidas em diferentes contextos de problematização - incluindo, bem entendido, aquele produzido pela ciência histórica - nos quais se estabelecem relações de temporalidade entre mundos passados, presentes e futuros. Trata-se de operar com as contribuições teóricas resultantes da interseção entre a Teoria e a Filosofia da História, no que essas incidem sobre o significante narrativa e sua articulação com a questão da temporalidade.

Nesse quadro de inteligibilidade, o significante narrativa histórica é compreendido como sendo a forma de significar a nossa experiência individual e coletiva com e no tempo. Além do significante tempo, outros elementos que compõem a cadeia de equivalências produzida para significar narrativa, tais como os termos intriga e enredo, ocupam um lugar de destaque. Se a tessitura de uma intriga diz respeito à concatenação de eventos na configuração de uma narrativa, o enredo constitui-se como contexto em meio ao qual a intriga se desenvolve e é tecida. Se a intriga é a ordenação temporal, o enredo é a possi- 
bilidade de tornar familiar o não familiar, o que Monteiro (2005) entende como indispensável para tornar possível aos alunos/as a atribuição de sentidos ao mundo e a compreensão da historicidade da vida social.

O saber histórico escolar - com o qual os sujeitos-discentes estabelecem relação na sala de aula - é entendido aqui como narrativa que permite acessar e explorar a potência das duas outras categorias anteriormente mencionadas para a reflexão sobre aprendizagens dessa disciplina escolar: verdade história e refiguração narrativa. Em relação à primeira, o que está em jogo é a possibilidade de continuarmos a reconhecer a importância de pautar o processo de ensino-aprendizagem no domínio do verdadeiro após as críticas contundentes à ideia de verdade absoluta metafísica na pauta pós-fundacional. Ainda que tenhamos argumentado que a aprendizagem - entendida com reposta de um sujeito-discente quando interpelado em contexto de formação, deixando entrever que a compreensão dessa relação particular com o saber deve concentrar-se no sujeito que aprende e não no objeto do aprendizado -, isso não significa que a escola deva abrir mão do seu compromisso com a ciência e, portanto, com um entendimento de conhecimento objetivo e verdadeiro.

Tal reconhecimento implica buscar outros caminhos para pensar a interface verdade-objetividade, distintos daquela sustentada em quadros teóricos hegemonizados na modernidade. No caso da História, essa questão tende a ser traduzida pelo que alguns consideram como o problema da distância ou diferença temporal entre passado e presente. Com efeito, o problema da verdade histórica tangencia a questão da temporalidade. Traduzida muitas vezes pela tensão entre fato e narrativa, essa questão se manifesta nas discussões internas ao campo, na possibilidade de construção de um discurso objetivo e verdadeiro que articule esses dois significantes. Os debates em torno do uso de fontes, da veracidade dos fatos apresentados, dos limites da subjetividade do historiador na construção do passado, estão relacionados às maneiras como a tessitura narrativa equaciona esse distanciamento entre passado e presente.

As soluções propostas dependem das diferentes matrizes teóricas do campo da História nas quais elas são pensadas e formuladas. Entre essas matrizes, destacamos as que vêm intensificando o diálogo com as correntes filosóficas que incorporam as contribuições do pós-fundacionismo. Importa sublinhar que, para esses filósofos, interessa menos a busca de equacionamentos para esse tipo de tensão do que a reformulação do problema no qual essa própria 
tensão emerge. Como argumenta Bevir (2015), ao problematizar as teorias históricas moderna e pós-moderna, a abordagem pós-fundacional, nessa área disciplinar, não considera como um problema a ser enfrentado a distância entre fato e narrativa, sob o argumento de que nenhuma proposição poderia ser referenciada fora do contexto de uma ampla rede de crenças. Nas palavras desse autor:

Uma análise pós-fundacionista dos fatos sugere que eles são sempre entrelaçados com as narrativas. Um fato adquire seu caráter como um resultado de sua relação com outros fatos. Uma narrativa não apenas explica os fatos postulando relações de significado entre eles, mas também revela o caráter desses fatos. Novamente, as narrativas não apenas revelam o caráter dos fatos, elas criam seu caráter e guiam nossas decisões sobre o que conta como um fato. Como não há observações puras, os historiadores parcialmente constroem o caráter de um fato através de suas narrativas. (BEVIR, 2015, p. 19)

Para os pós-fundacionistas, um fato histórico não é dado, tampouco construído objetivamente por meio de um método. Sua construção se faz em meio a disputas por sua hegemonização em uma dada comunidade epistêmica, na qual as regras do jogo são pactuadas. Entre elas, a importância de incorporar certos elementos metodológicos como, por exemplo, o trabalho com as fontes. A produção do conhecimento da História não se reduz, portanto, a uma questão de método, mas é um processo de comparação entre narrativas. Isso não significa, no entanto, assumir uma perspectiva relativista, e sim redefinir o padrão de objetividade com o qual realizamos as análises.

A opção pela comparação entre as narrativas disponíveis em relação aos fatos em questão como caminho alternativo para a produção de conhecimento objetivo significa que a fronteira do que pode ou não pode ser considerado como conhecimento histórico verdadeiro, ao invés de ser estabelecida a partir da autenticidade de uma narrativa por meio da verificação dos fatos, isto é, de "um confronto entre a narrativa e os fatos evidentes" (Bevir), produz-se por meio da "comparação entre narrativas em termos de seu relativo sucesso em relacionar os fatos a outros entre si destacando suas similaridades, diferenças e conexões" (ibidem).

Esse entendimento de conhecimento objetivo por meio da comparação entre narrativas ou histórias rivais remete, no entanto, à questão de critérios, 
cujo enfrentamento não pode ser negligenciado. O desafio consiste, assim, em disputar igualmente os critérios de objetividade e de veracidade nessa perspectiva. Nesse movimento, alguns critérios disponíveis, como por exemplo "a precisão para os fatos em questão, a cobertura completa dos fatos relevantes, a consistência e a compatibilidade com os padrões de evidência em questão, e uma progressiva, frutífera e aberta relação a outras narrativas" (ibidem), merecem ser considerados e explorados. Entendemos que o processo de comparação nessa perspectiva abre possibilidades para construir critérios de objetividade para as narrativas históricas que possam se inscrever entre as exigências da estética/imaginação que lhes confere verossimilhança e os regimes de verdade hegemonizados contingencialmente pelos pesquisadores e professores/ as nessa área disciplinar de forma a garantir que essas narrativas mantenham-se no domínio do verdadeiro.

Se retomarmos a questão da articulação entre passado e presente na construção narrativa a partir de um outro padrão de objetividade, pautado na postura epistêmica pós-fundacional, dois aspectos precisarão ser levados em conta. Ao contrário do que nos alerta Rancière (2011) sobre a herança da historiografia ocidental em relação à antiguidade clássica, em uma perspectiva historiográfica pós-fundacional, o devir da história nunca é governado por leis universais de natureza pré-linguísticas. Seu movimento é pensado como tendo uma racionalidade sustentada nas teorias e crenças do presente e como resultante contingente de incongruências entre as múltiplas temporalidades que se encontram e tensionam-se nos discursos, produzindo novos rearranjos sociais. Remontar o tempo significaria, então, compreender os fatos segundo os limites do que é possível supor sobre o contexto de uma dada época, que muitas vezes distancia-se de nós por um número incontável de camadas de sentido.

A questão da aprendizagem de um conhecimento histórico verdadeiro implica, pois, o enfrentamento com um problema da conexão entre o que é estranho e o que é familiar, entre passado e presente, trazendo para a reflexão aqui pretendida uma temática clássica do debate historiográfico traduzida no espectro do anacronismo. Que efeitos no entendimento desse termo a abordagem pós-fundacional produz? Ao postular a inexistência do fato em si, e simultaneamente reconhecer uma dada correlação de fatos em uma narrativa, o pós-fundacionismo concedeu maior liberdade ao historiador e ao professor de História para interrogar o passado sobre qualquer coisa, usando palavras 
ou expressando preocupações do presente sem fixá-las no tempo. No entanto, segundo Bevir (2015), é preciso diferenciar dois tipos de anacronismo: a atribuição de crenças anacrônicas e o uso de palavras anacrônicas para evocar crenças. Esse autor lembra que só o primeiro caso é um problema.

A questão para os pós-fundacionistas passa a ser, então, o grau de adequação de conceitos abstratos para casos mais particulares, dadas certas circunstâncias. Assim, o pós-fundacionismo substituiu a ênfase dada à dimensão estética (verossimilhança) da narrativa pela ênfase no problema filosófico da adequação da universalidade dos conceitos do presente para analisar o passado. Nesse sentido, o anacronismo só pode ser um problema se for o caso de atribuir-se uma crença a uma dada época que, dadas as informações disponíveis, não poderiam ainda ter sido pensadas (BEVIR, 2015), mas não pode ser um problema de palavras fora do seu tempo.

Esse caminho parece-nos promissor para pensar a aprendizagem em História, e vem sendo explorado por pesquisadores do campo (LORAUX, 1992; SILVA, 2017; MONTEIRO, 2005) que reconhecem a potência analítica da reatualização do sentido do termo analogia ou, se preferirmos, da produtividade, nos processos de ensino-aprendizagem da prática controlada do anacronismo. O deslocamento do veto concedido ao anacronismo nessa perspectiva significa que o professor de História não pode lançar mão, no decorrer do processo de ensino-aprendizagem, de acontecimentos ou ideias do passado que não se encaixem no quadro do que conhecemos sobre as crenças da época, isto é, que não pareça verossímil. Em contrapartida, ele amplia o campo de possibilidades de fixação de sentidos dos sujeitos envolvidos nesse processo de mobilizarem sua imaginação e capacidade criativa.

Essa abordagem vai igualmente ao encontro de estudos como os de Pereira e Marques (2013) sobre a necessidade pedagógica e científica de pensar os aspectos estéticos das narrativas e das formas de expressão do conhecimento utilizados por professores/as para criar e recriar conceitos históricos em sala de aula. Além disso, a criatividade e a imaginação são faculdades altamente desenvolvidas na infância e na adolescência, contribuindo ainda mais para que essas dimensões assumam um lugar de importância quando se trata da reflexão sobre aprendizagem, percebida, aqui, como uma resposta discente em meio às interpelações das narrativas históricas em contexto escolar.

Como sugere Hilary Cooper (2012) a partir da sua pesquisa com crianças 
de 11 anos de idade, consideramos que a imaginação histórica desenvolve-se por meio da construção de suposições válidas sobre como as coisas foram feitas e usadas no passado, considerando o que elas deviam significar para as pessoas na época. Segundo essa autora, esse é o veículo por meio do qual a sensibilidade se expressa. Fantasiar sobre as possibilidades de vivência do passado também significa conferir a essas vivências um "efeito real".

Ricoeur considera "que esse entrelaçamento da ficção à história não [enfraquece] o projeto de representância desta última, mas [contribui] para a sua realização" (1997, p. 323). Ao contrário do labor científico e sua preocupação em comprovar o que se diz, a criação artística quer provocar a intuição, quer comunicar de modo vívido, quer causar a sensação de imersão. Imersão na realidade que procura comunicar. Essa forma de enfrentamento da questão da objetividade e verdade histórica remete à reflexão em torno da terceira categoria anteriormente mencionada, que recoloca em cena o papel incontornável do sujeito do conhecimento no processo de aprendizagem.

No que diz respeito à refiguração narrativa (RICOEUR, 1994), argumentamos que, embora essa categoria não tenha sido formulada no quadro pós-fundacional, ela se apresenta como uma estratégia para pensar, no âmbito da História, a interface aprendizagem-resposta em consonância com as críticas radicais às perspectivas essencialistas e deterministas formuladas pelo pós-fundacionismo. Para sustentar esse argumento, nos apoiamos nas contribuições teóricas formuladas no quadro hermenêutico ricoeuriano, em particular na ideia de círculo hermenêutico, que se inscreve no próprio entendimento de narrativa defendido por esse filósofo.

É justamente a preocupação em construir e expor o mundo em perspectiva temporal que leva Ricoeur a fixar um sentido particular para o significante narrativa histórica. Segundo ele, esse mundo precisa tornar-se inteligível e é a narrativa que permite que ele assim o seja, ao delinear os traços da experiência temporal. Na hermenêutica ricoeuriana, a inteligibilidade narrativa se dá num triplo movimento interpretativo - o círculo hermenêutico - não linear, contingente e sempre incompleto: prefiguração (competência de acompanhar uma história); configuração (construção da intriga, do texto); refiguração (encontro do mundo do texto com o mundo do leitor), de forma que é na narrativa que o sentido se constitui como ação.

Cada uma dessas etapas do círculo é chamada de mimese e, embora sejam 
numeradas (prefiguração - mimese I ${ }^{2}$ configuração - mimese II ${ }^{3}$ refiguração - mimese III), elas não ocorrem de forma linear, mas relacionam-se dialeticamente. De acordo com Ricoeur (1994), apesar da passagem da mimese I à mimese III suscitar uma ideia de círculo vicioso, no qual a mimese II seria apenas uma ponte, essa ideia pode ser refutada, pois, segundo ele, trata-se de "uma espiral sem fim que faz a meditação passar sempre pelo mesmo ponto, mas numa altitude diferente" (RICOEUR, 1994, p. 112).

Tendo em vista o escopo deste artigo, centramos nossa reflexão no terceiro movimento (mimese III) do ciclo hermenêutico. Partimos da hipótese de que a aprendizagem-reposta ocorre especialmente nesse momento do encontro do mundo do leitor com o mundo do texto. É a mimese III a responsável pela transição da configuração à refiguração que é operada pelo ato de leitura. Trata-se do espaço-tempo da compreensão da configuração a partir de uma tomada de consciência, o que garante a presença da subjetividade. É ali que as narrativas oferecidas pelo professor são ressignificadas à luz das experiências e expectativas. É ali que se desenvolve o que Cerri (2010) nomeia como competência narrativa, que sintetiza as dimensões do tempo, do valor e da experiência. A competência narrativa "resulta de um aprendizado, e se reconstrói continuamente, em função das novas experiências e mudanças na realidade e do diálogo com novos argumentos" (CERRI, 2010, p. 274).

Assim, ao ter contato com narrativas escolares, os sujeitos-discentes as leem conforme sua intratemporalidade se manifesta, e de acordo com as apropriações que fazem do contexto macro e micro nos quais estão inseridos. A intriga tecida na configuração do texto escolar, seja ele do/a docente e/ou do livro didático, não se esgota sem a leitura daquele a quem a narrativa histórica foi endereçada, de forma que o texto nunca está absolutamente fechado, estando, portanto, permanentemente à espera de outras possíveis leituras. A leitura retoma o ato configurante da intriga de forma a fazer parte do texto também, não havendo, portanto, oposição entre escrita e leitura. Isso significa que a formação de enredo, no caso da narrativa histórica,

traz a possibilidade de apreendê-la como estando sempre aberta a múltiplas inteligibilidades produzidas no encontro entre o mundo do texto (a história ensinada nos livros didáticos e/ou nas aulas dessa disciplina, por exemplo) e o mundo do 
leitor (as diferentes subjetividades posicionadas como alunos/as de história em contextos escolares). (GABRIEL, 2012, p. 202).

No círculo hermenêutico, a temporalidade que compõe o mundo preconfigurado é também transformada. Uma intriga específica é finalizada e precisa ser comunicada para ser reaberta em novo ato configurante por meio da interpretação, pois a recepção de um texto implica comunicação, uma vez que toda narrativa projeta um mundo e seus horizontes, deixando entrever possibilidades de encontros entre autor-leitor (docente-discente), permitindo a compreensão sobre as aprendizagens históricas como refigurações das experiências temporais por meio da narrativa.

Ao investir na importância da quebra de barreiras entre o mundo do texto e o mundo do leitor para a compreensão da narrativa histórica em toda sua complexidade, a refiguração narrativa permite operar com a ampliação do campo das racionalidades, incorporando um entendimento de verdade histórica que borra as fronteiras entre uma razão argumentativa e persuasiva, que não negligencia os regimes de verdade pactuados nas comunidades epistêmicas dessa área (distinção entre memória e História, o trabalho crítico das fontes etc.), sem que isso signifique a exclusão do debate das contribuições dos campos da ética, da política e dos afetos.

É preciso sublinhar ainda que o sentido de refiguração aqui defendido, a partir do diálogo com Ricoeur, não é completamente livre e tampouco reatualiza o sujeito pleno do Iluminismo, pois o texto, para além dos limites que apresenta, também constrange os processos de leitura, as possibilidades de refiguração. A dialética entre liberdade e coerção é interna ao processo criador e atravessa todo o processo hermenêutico. E é o próprio Ricoeur que contribui para esse questionamento da plenitude do sujeito:

enquanto o leitor incorpora - consciente ou inconscientemente, pouco importa - os ensinamentos de suas leituras à sua visão de mundo, para aumentar a sua legibilidade prévia, a leitura é para ele algo diferente de um lugar onde ele se detém; ela é um meio que ele atravessa. (RICOEUR, 1997, p. 303-304, grifos nossos) 


\section{REFIGURAÇÕES DISCENTES DE NARRATIVAS HISTÓRICAS PRODUZIDAS NAS SALAS DE AULA}

Só na leitura o dinamismo de configuração encerra seu percurso. E é para além da leitura, na ação efetiva, instruída pelas obras consagradas, que a configuração do texto se transforma em refiguração. (RICOEUR, 1997, p. 275-276, grifos nossos)

Nosso escopo neste terceiro e último bloco de reflexões é explorar evidências empíricas sobre formas de pensar de outro modo a questão da aprendizagem em História, tal como viemos defendendo ao longo desta escrita. Interessa-nos explorar possibilidades de pensar essa questão de forma a não limitá-la à sua dimensão cognitiva, sem todavia ignorar ou negar sua devida importância nesse processo. Selecionamos três fragmentos de refigurações narrativas de discentes da educação básica que foram produzidas por meio de uma atividade pedagógica de um tema sensível no campo do Ensino de História: a temática da escravidão. ${ }^{4}$

O primeiro fragmento (Narrativa 1) foi produzido por uma aluna do oitavo ano do Ensino Fundamental a partir da pintura Castigo de Escravo (Overseers punishing slaves on a rural estate, produzida por Debret em 1834). Para a realização da atividade, foi solicitado às/aos alunas/os que criassem uma história a partir da imagem. As outras duas narrativas (2 e 3) foram produzidas por alunas do nono ano, que criaram uma ficção a partir das memórias de S. Julião sobre a abolição da escravatura no Brasil em 1888, que lhe foram contadas pelo seu pai. ${ }^{5}$

Importa sublinhar que, em ambas as atividades, nenhuma outra explicação ou aula sobre os temas da escravidão ou da abolição antecedeu ao exercício naquelas turmas. Foram aulas introdutórias da temática. No entanto, isso não significa que esses sujeitos-discentes não tenham sido já interpelados nas aulas de História dos anos anteriores pelas narrativas históricas escolares da escravidão, ou tido contato com o tema em outros espaços. Como mencionado anteriormente, embora esses fragmentos tenham sido tomados aqui como refigurações narrativas, eles expressam diferentes camadas de articulação entre passado e presente, bem como carregam movimentos de prefiguração e configuração narrativa.

As três narrativas a seguir são de autoria de três adolescentes do Ensino 
Fundamental, produzidas em contexto escolar a partir de orientações de seus respectivos docentes de História.

Narrativa 1: Querido diário, hoje eu vi uma coisa que sempre me deixou triste, eu sempre quis fazer a diferença, não gostava de ver essas cenas horríveis, porém como as mulheres não tinha poder ou mesmo direito para nada tive que ficar quieta, hoje vi a cena de um empregado do papai, batendo em um escravo só por que o tadinho olhou para mim, quando eu olhei para ele o empregado começou a bater e a dizer que ele nunca ia ficar com alguém da nobreza, que um pobre coitado nunca ia ser percebido por uma dona linda como eu, o escravo já cansado de tanto apanhar olhava com lágrimas nos olhos, eu estava pensando no que ele devia estar pensando eu pensei que na mente dele, ele estava dizendo: - não aguento mais estou cansado de ser escravo, eu queria uma chance de ser rico, queria a mão da senhorita letícia, mas ela nunca que ia gostar de mim. E eu sem reação vendo aquele escravo apanhar por causa de mim, peguei e corri para cima do empregado e dei uns tapas nele, peguei e mandei o escravo ir embora, e papai não gostou muito mas eu tinha que fazer alguma coisa, peguei e fui para meu quarto, pensando que um dia o pobre coitado ia voltar para me agradecer e isso foi o meu dia, defensora dos escravos. (Aluna do oitavo ano, 13 anos de idade, grifos nossos)

Narrativa 2: Era uma vez uma mulher chamada Maria das Graças que vivia no Brasil em 1888. Um belo dia ela estava passeando em seu jardim com seu esposo que se chamava Alberto. Nisso um ex-escravo chegou na casa de Maria para cumprimentá-la, Alberto olhou para o ex-escravo que se chamava Josué, e lhe disse: - Saia de perto da minha esposa você é negro e um ex-escravo da época da abolição da escravatura. Aí o ex-escravo lhe respondeu: - Falasti bem meu caro amigo. Exescravo não sou mais então quer dizer que eu posso cumprimentar a senhorita Maria da Graça, por que sim ela foi uma grande "amiga" para mim. Alberto furioso solta da mão de Maria e entra pra sua casa, e Maria fica lá fora conversando com o ex-escravo. (Aluna do nono ano, 15 anos de idade, grifos nossos)

Narrativa 3: Alguns meses antes da abolição da escravatura, eu estava tendo um caso com uma moça muito linda, porém ela era esposa do meu senhor. Ficamos muito tempo mantendo esse caso, nos encontrávamos todas as tardes no cafezal, um dia quase fomos pegos pelo capataz que por sua vez contou pro meu senhor. Meu senhor ficou desconfiado começou a seguir a gente e nos pegou no fraga, eu fui direto pro tronco e Lindalva foi arrastada pelos cabelos até o casarão eu pelo milagre sobrevivi, já meu patrão lavou sua honra. Depois desse episódio o patrão 
voltou a me procurar só que por sorte eu consegui fugir e ele furioso continuou me procurar só parou a procura no dia 13 de maio de 1888. O meu ex-senhor ficou muito revoltado pela abolição e junto com os outros fazendeiros e militares que por sua vez estavam insatisfeitos com o monarca d. Pedro II, em 15 de novembro de 1889, eles deram o golpe e proclamaram a República do Brasil. E eu virei volante de outras fazendas. (Aluna do nono ano, 15 anos de idade, grifos nossos)

O ponto de vista escolhido para analisar esses fragmentos é menos o da aquisição de algo externo ao sujeito que supostamente o discente carece, do que da relação com o saber histórico estabelecida por esse sujeito-discente. Mais especificamente, interessa-nos interpretar a forma de enfrentamento entre passado e presente mobilizadas nessas narrativas, a articulação entre as diferentes racionalidades que são acionadas nessa mobilização, o lugar da imaginação nesse movimento, ou ainda, eventualmente, a prática do uso de anacronismos na tentativa de equacionar a distância entre passado e presente.

Acreditamos que seja possível e válido supor que os enredos produzidos nessas narrativas traduzam a preocupação das alunas em encontrar as figuras temporais adequadas para que a narrativa faça sentido. Tratou-se de um exercício de fabulação. No entanto, queremos enfatizar que tal exercício não significou a ausência de compromisso do sujeito-docente com a veracidade da narrativa, senão lhe permitiu substituir a preocupação frequente com a verdade dos fatos pela preocupação com a verossimilhança da narrativa.

Os trechos que destacamos contêm marcas de temporalidade inscritas na narrativa, especialmente na forma de diferença entre passado e presente, mas também na forma de uma sutil analogia entre eles. A diferença aparece, por exemplo, na ideia de submissão feminina que se expressa na primeira narrativa como reconhecimento da própria incapacidade de agir ("como as mulheres não tinha poder ou mesmo direito para nada tive que ficar quieta”). Na segunda, aparece na forma de uma mulher sem falas ou agência e que é alvo da disputa entre dois homens ("Saia de perto da minha esposa..."/“Ex-escravo não sou mais...”).

As alunas também conceberam a relação possível entre uma mulher livre e um escravo de três modos diferentes, embora todos eles envolvendo alguma forma de amor proibido. Enquanto na Narrativa 1 a mulher sente compaixão e empatia diante do sofrimento do escravo ("eu estava pensando no que ele devia estar pensando eu pensei que na mente dele"), a segunda sempre tratou-o de modo fraternal e a terceira teve um "caso" extraconjugal com o escravizado. As relações assimétricas de poder do contexto são retratadas nos trechos em situa- 
ções concretas como impossibilidade de fazer ("nunca ia ficar com alguém da nobreza"/ "Saia de perto da minha esposa você é negro e um ex-escravo da época da abolição da escravatura”), ou em forma de um conceito que marca a impossibilidade de ser, como no trecho "ela foi uma grande 'amiga' para mim", em que o sentido das aspas indicam a diferença - ou a distância histórica - entre o significado de amizade para a aluna e o significado que um escravo poderia ter dado na época para uma relação semelhante, mas nunca idêntica ao presente. Os conflitos sociais decorrem dessas relações assimétricas e o sofrimento do escravo ou da mulher se expressa na dramaticidade do enredo ("o escravo já cansado de tanto apanhar olhava com lágrimas nos olhos"; “Alberto furioso solta da mão de Maria"; "eu fui direto pro tronco e Lindalva foi arrastada pelos cabelos até o casarão eu pelo milagre sobrevivi, já meu patrão lavou sua honra").

A questão que se coloca, em termos de aprendizagem, não é a de avaliar se essas relações realmente se passavam desse jeito, mas se elas podem ser consideradas plausíveis em função das crenças da época. Isto é, se podemos ou não atribuir essas situações ou ideias àquelas pessoas e àquela época. Isso pressupõe sair do terreno onde a aprendizagem da História é pensada em termos de como as coisas eram no passado para propor um exercício de imaginação em que o essencial seja refletir sobre como as coisas poderiam ou não ter sido.

Nessas narrativas, a temporalidade não se expressou tanto no cenário em que os acontecimentos se passam (de certa forma somente a Narrativa 3 demonstrou essa preocupação: "cafezal", "ir para o tronco" e "casarão") e nem na preocupação com a cronologia do calendário (presente apenas na Narrativa 3, novamente), mas na caracterização da mentalidade da época. Na construção dessas narrativas, se o conceito de nobreza (Narrativa 1) serve para destacar a diferença entre as crenças do passado e do presente quanto às possibilidades de relacionamento, a alternância entre as identidades de "senhor" e "patrão" (assim como o caso do significado das aspas em "amiga") na Narrativa 3 sugere uma possível visita ao passado sob o signo da analogia entre as relações do escravizado com o senhor e do patrão com o empregado. Embora essas relações sejam de natureza diferente, a comparação entre elas não é necessariamente absurda. Pelo contrário, dessa aparente confusão pode-se pelo menos deduzir que há nela a ideia de que a relação escravizado/senhor, assim como a relação empregado/patrão, carrega a ideia de relação de trabalho.

Essa breve análise empírica permite duas conclusões que se referem à relação estabelecida com o saber histórico escolar por parte desses sujeitos-discentes. 
A primeira é que, a partir desses fragmentos narrativos, podemos afirmar que, para elas, o conceito de escravidão remete a situações de conflito que se dão em uma ordem social hierárquica, marcada pela desigualdade entre os sexos e entre as raças. A segunda é que, nesses casos, o passado difere do presente. O que nos interessa é que a escravidão para esses discentes não representa apenas um passado traumático deixado para trás, mas seu significado remete a todo um conjunto de crenças e modos de ser e agir cujos rastros estão ainda presentes.

Nesse sentido, gostaríamos de pensar a questão da aprendizagem como desejo de estabelecer novas conexões entre os tempos e de definir direcionamentos inéditos para o futuro. É justamente certo anacronismo o que permite a conexão entre o possível e o impossível, a incorporação de ideias, modos de ser e modos de fazer do passado que embaralham as temporalidades e a antecipação do devir segundo esses modos específicos que resgatam uma temporalidade e uma duração, igualmente específicos.

É possível pensar a questão da aprendizagem nessa perspectiva e ainda assim operar com um conhecimento científico? Buscamos argumentar ao longo deste artigo que sim. Defendemos que o regime de verdade com o qual os historiadores operam não é mais necessariamente identificado pela validade do método, tampouco somente pela verossimilhança do relato, mas conforme o significado que os fatos poderiam ter tido para as pessoas da época segundo as informações que temos sobre o período. Esse entendimento reforça a pertinência de criarmos um outro padrão de objetividade para o conhecimento histórico escolar que incorpore a possibilidade do uso controlado de anacronismo.

Nesse sentido, nossa intenção foi demonstrar que os alunos podem até empregar palavras e ideias do presente para representar o passado, sem que isso se caracterize necessariamente como anacronismo, desde que se considere que o grau de precisão com que um conceito captura as crenças que queremos narrar varia de acordo com o propósito e o nível de abstração da narrativa. Aprender História não é apenas ser receptáculo das informações e dos conceitos já definidos, e sim uma experiência com o passado por meio da imaginação para recriar os conceitos, refletir sobre a historicidade do presente e, o que talvez seja o mais importante, atribuir racionalidade histórica crítica ao sofrimento e demais experiências sensíveis. E isso, em nossa conjuntura política atual, não é pouca coisa. 


\section{REFERÊNCIAS}

ALLIEU, Nicole. De l'histoire des chercheurs à l'histoire scolaire. In: DEVELAY, M. (Org.). Savoirs scolaires et didactiques de disciplines: une encyclopédie pour aujourd'hui. Paris: ESF, 1995.

BEVIR, Mark. Porque a distância histórica não é um problema. História da Historiografia, Ouro Preto, Universidade Federal de Ouro Preto, n. 18, ago. 2015.

BIESTA, Gert. Para além da aprendizagem: educação democrática para um futuro humano. $1^{\text {a }}$ ed.; 1. Reimp. Belo Horizonte: Autêntica Editora, 2017.

BONDÍA, Jorge Larrosa. Notas sobre a experiência e o saber de experiência. Revista Brasileira de Educação, n. 19, jan./abr., 2002.

CAIMI, Flavia Eloisa. Por que os alunos (não) aprendem História? Reflexões sobre ensino, aprendizagem e formação de professores de História. Tempo. Revista do Departamento de História da UFF, v. 11, p. 27-42, 2006.

CAIMI, Flavia Eloisa. O que precisa saber um professor de História? História e Ensino, Londrina, v. 21, n. 2, p. 105-124, jul./dez. 2015.

CAINELLI, Marlene Rosa. Educação Histórica: perspectivas de aprendizagem da História no ensino fundamental. Educar Em Revista (Impresso), Universidade Federal do Paraná, v. 164, p. 57-72, 2006.

CERRI, Luis Fernando. Didática da História: uma leitura teórica sobre a História na prática. Revista de História Regional 15(2): 264-278, Inverno, 2010.

COOPER, Hilary. Ensino de história na educação infantil e anos iniciais: um guia para professores. Traduzido por Rita de Cássia K. Jankowski, Maria Auxiliadora M.S. Schmidt e Marcelo Fronza. Curitiba: Base Editorial, 2012.

COSTA, Hugo Heleno Camilo; LOPES, Alice Casimiro. A comunidade disciplinar em Goodson: impasses em um registro pós-estrutural. Revista Brasileira de Educação, v. 21, n. 67, out.-dez., 2016.

FREITAS, Ana Beatriz Machado de. A dimensão estética na aprendizagem: desocultando pontos cegos. Educação \& Realidade, Porto Alegre, v. 41, n. 2, p. 575-589, abr./jun. 2016.

GABRIEL, Carmen Teresa. Relação com o saber: uma proposta de releitura pós-fundacional. In: LOPES, A.C.; OLIVEIRA, A.L.M. de; OLIVEIRA, G.G.S. de (Orgs). A teoria do discurso na pesquisa em educação. Recife: Editora UFPE, 2018.

GABRIEL, Carmen Teresa. Teoria da História, Didática da História e narrativa: diálogos com Paul Ricoeur. Revista Brasileira de História. São Paulo, v. 32, nº 64, p. 187$210-2012$.

GABRIEL, Carmen Teresa. Um objeto de ensino chamado História: a disciplina de História nas tramas da didatização. 2003. Tese (Doutorado em Educação) - PUC-RJ, Rio de Janeiro.

HALL, Stuart. Quem precisa da identidade? In: SILVA, Tomaz Tadeu; HALL, Stuart; e 
WOODWARD, Kathryn (Orgs.). Identidade e diferença: a perspectiva dos estudos culturais. Petrópolis: Vozes, 2000.

LORAUX, Nicole. Elogio do anacronismo. In: NOVAES, Adauto (Org.). Tempo e história. São Paulo: Companhia das Letras, 1992.

MARCHART, Oliver. El pensamento político posfundacional: la diferencia política em Nancy, Lefort, Badiou y Laclau. Buenos Aires: Fondo de Cultura Económica, 2009.

MARTINS, Marcus Leonardo Bomfim. A (im)possibilidade da avaliação no ensino de História: uma análise a partir de exercícios de livros didáticos. 2019. 336f. Tese (Doutorado em Educação) - UFRJ, Rio de Janeiro.

MISTURA, Letícia. Entre tensões e proposições: um estado do conhecimento sobre a aprendizagem histórica no Brasil em dissertações e teses (2005-2018). 2019. $166 f$. Dissertação (Mestrado em Educação) - UPF, Passo Fundo.

MONIOT, H. La dictatique del 'histoire. Paris: Nathan, 1993.

MONTEIRO, Ana Maria. Entre o estranho e o familiar: o uso de analogias no Ensino de História. Cad. Cedes, Campinas, vol. 25, n. 67, p. 333-347, set./dez. 2005.

MONTEIRO, Ana Maria. Professores de História: entre saberes e práticas. Rio de Janeiro, Editora Mauad, 2007.

MOREIRA, Carlos Gustavo Costa. Sobre a aprendizagem dos regimes de sentido do tempo histórico escolarizado: parâmetros críticos para estudo curricular sobre ensino de História para o $6^{\circ}$ ano do Ensino Fundamental. 2016. 212f. Dissertação (Mestrado Profissional em Ensino de História). Seropédica, 2016.

PEREIRA, Nilton Mullet; MARQUES, Diego Souza. Narrativa do estranhamento: ensino de História entre a identidade e diferença. PLURES Humanidades. Ribeirão Preto/SP, v. 14, n. 1, 2013.

RANCIẼRE, Jacques. O conceito de anacronismo e a verdade do historiador. In: História, verdade e tempo. Marlon Salomon (Org.). Chapecó, SC: Argos, 2011.

RICOEUR, Paul. Tempo e narrativa - Tomo I. Campinas: Papirus, 1994.

RICOEUR, Paul. Tempo e narrativa - Tomo III. Campinas: Papirus, 1997.

ROCHA, Helenice Aparecida Bastos. O lugar da linguagem no ensino de História.. Tese (Doutorado em Educação). UFF, Niterói, 2006.

SCHIMIDT, Maria Auxiliadora Moreira dos Santos. Concepções de aprendizagem histórica presentes em propostas curriculares brasileiras. História Revista, Goiânia, v. 14, n. 1, p. 203-213, jan./jun. 2009.

SILVA, Daniel Pinha. O lugar do tempo presente na aula de história: limites e possibilidades. Revista Tempo e Argumento, Florianópolis, v. 9, n. 20, p. 99 - 129. jan./abr. 2017. jan./abr. 2017.

WANDERLEY, Sonia. Narrativas contemporâneas de história e didática da história escolar. In: Ana Maria Mauad; Juniele Rabêlo de Almeida;Ricardo Santhiago (Orgs.). História Pública no Brasil: sentidos e itinerários. Vol. 1, 1 ed. São Paulo: Letra e Voz, 2016. 


\section{NOTAS}

${ }^{1}$ De acordo com Moreira (2016, p. 144), “essa nova vertente de pesquisa da área das ciências humanas e sociais ficou conhecida como Didática da História (Alemanha), History Education (Reino Unido), Educação Histórica (Portugal e Brasil), entre outras denominações de acordo com a geografia e o idioma".

${ }^{2}$ Corresponde ao tempo prático do senso comum da linguagem, diz sobre uma pré-compreensão do mundo, que diz respeito a estruturas inteligíveis (estágio onde todos estão inseridos), fontes simbólicas (leituras das ações de acordo com o contexto), e intratemporalidade, que corresponde à forma como lidamos com o tempo, e do qual é impossível escapar, pois existe independente de você, sendo, portanto, anterior à sua tomada de consciência.

${ }^{3}$ Representa a articulação entre tempo e narrativa em uma intriga, trata-se da tessitura da intriga, do tempo configurado ou, em outros termos, da realidade organizada textualmente pelo narrador. É a produção de uma narrativa que articula vários momentos em um determinado contexto para um público específico, o que exige uma ordenação temporal.

${ }^{4}$ As alunas foram orientadas a criar uma história a partir dos materiais disponibilizados, e que ela fosse contada em forma de um dia na vida de uma pessoa qualquer que eles imaginam ter vivido no Brasil à época em que vigorava aqui o regime escravista. Foi dito que não era importante se a história seria contada em primeira ou em terceira pessoa, apenas que os acontecimentos se passassem no período de um dia na vida dessa personagem e que eles escrevessem na forma de diário. As adolescentes levaram em média quarenta minutos para concluir a tarefa, e no final entregaram ao professor a folha pautada que haviam recebido no início.

${ }^{5}$ A narrativa do S. Julião faz parte do resgate de memórias do cativeiro promovido pelo LABHOI-UFF. Segue a sua transcrição: "Depois que terminou a escravidão meus pais não ficaram na mesma fazenda. Os escravos foram todos se mudando, foram saindo. No tempo do cativeiro havia muito café aqui, mas os camaradas foram largando os fazendeiros... iam embora, saíam da fazenda, não ficavam mais. E os fazendeiros queriam pagar eles pra ficar, mas eles não ficavam. Meu pai trabalhava assim de volante...saía de uma fazenda, trabalhava na outra, não era colono, trabalhava os dias que precisava trabalhar. Quem ficava na fazenda tinha que continuar a morar na senzala. Ninguém queria. No final, cada um já tinha suas casas na roça. Um tinha uma casa aqui, outro lá. Casas separadas um do outro. Todo mundo tinha uma casa na roça. (S. Julião, RJ, 81 anos, 27/10/95)”. Disponível em: http://www.labhoi. uff.br/sites/default/files/narcht05.pdf. Para maiores informações ver http://www.labhoi.uff. br/narrativas/chaves-tematicas. Acesso em: 27 ago. 2020.

Artigo recebido em 31 de agosto de 2020. Aprovado em 08 de outubro de 2020. 